\title{
Reviewing the Effectiveness of Contribution of Microstrip Antenna in the Communication System
}

\author{
R. J. Kavitha' ${ }^{1}$, H. S. Aravinda ${ }^{2}$ \\ ${ }^{1}$ Research Scholar Visvesvaraya Technological University, Belagavi, India \\ ${ }^{2}$ Proferssor \& Head of the Department of Electronics \& Communication Engineer, JSSATE, Bangalore, India \\ Email: kavitharjkkiran@gmail.com
}

How to cite this paper: Kavitha, R.J. and Aravinda, H.S. (2017) Reviewing the Effectiveness of Contribution of Microstrip Antenna in the Communication System. Open Journal of Antennas and Propagation, 5, 47-62.

https://doi.org/10.4236/ojapr.2017.52005

Received: May 6, 2017

Accepted: June 23, 2017

Published: June 26, 2017

Copyright $\odot 2017$ by authors and Scientific Research Publishing Inc. This work is licensed under the Creative Commons Attribution International License (CC BY 4.0).

http://creativecommons.org/licenses/by/4.0/

\begin{abstract}
The wireless communication serves the efficient information among two or more points wirelessly. Antenna is the main component in the communication, which radiates and receives the radio waves or in broad way. The antenna also plays a role of impedance matching device, which performs the matching of impedances like free-space \& transmitter and receiver impedances at receiver end. The antennas can be categorized as Wire Antenna, Reflector Antenna, Multi-strip Antenna, Aperture Antenna, Lens Antenna, and Array Antenna. In this paper, the Multi-strip Antenna fundamentals are discussed with its categorization. In this paper various aspects of the Multi-strip antenna are discussed along with the existing researches in it. A research gap is formulated based on the research survey and presents a future scope of research. The existing research gap in Multi-strip Antenna is formulated along with the future line of research in order to overcome the existing research gap.
\end{abstract}

\section{Keywords}

Antenna, Feeding Technique, MSA, Wireless Communication

\section{Introduction}

The fact is known that the wireless communication is greatest technology, which is serving efficient information among two or more points wirelessly [1]. The wireless communication technology includes various types such as satellite, mobile, IR etc. [2]. Antenna is the main component in the communication, which radiates and receives the radio waves or in broad way [2]. The antenna also performs like the "transducer" which converts the one type of energy into another 
[3]. Also, the antennas convert the electromagnetic radiations into electrical energy at receiving end to radiate maximum power in space to fulfill the maximum power transfer [2] [3]. During the transmission mode, antennas are used to radiate the electromagnetic waves and during the receiving mode, antennas act as sensors of electromagnetic waves. The antenna also plays a role of impedance matching device, which performs the matching of impedances like freespace \& transmitter and receiver impedances at receiver end [3]. Numerous communication channel/radar systems operate with single polarized, constant beam antennas and also have consequently to manage unaligned polarization and beams subjecting desired signal degradation. Since recent decades, numerous new antennas were given which manage these challenges [1], an extremely significant methodology smart antenna system, where beam-forming abilities act as a significant ingredient [4]. For some reasons, it is adequate to control the beam just in one direction, like in automatic distance control [4]. In automotive aspects, most reflective items and obstacles are situated on the ground around the car, at any rate the greater part of those which must be recognized by a programmed separate control framework. The acknowledgment of any conceivable obstacle must work totally precisely in the event of autonomous aspects [5].

In order to attain better features of smart antenna by Microstrip Patch Antenna (MsPA) array, the Microstrip antenna (MsA) quality faction is very high, which can be decreased by enhancing the dielectric substrate [6]. Because of higher thickness, some of the unwanted powers will be occurred due to surface wave. But thickness and power loss increases occur by surface-wave (SW) [7]. However, the SWs will be optimized due to photonic band gap structures. Recent researches on MsAs have worked on data transmission variation and on multifunction operations [8]. An MsA is consisting of a metallic fix over the dielectric substrate having backing ground plane. Also, contains units like dielectric substrate, a thin-level metallic area i.e., fix, ground-plane and feed for RF control [9]. MsAs are a promising other option to the future remote innovations in different segments including, military, common, and business. This is for the most part because of their ease, little size, and lightweight, and in addition simple creation and incorporation with any planar manufacture innovation including smaller than usual half and half microwave coordinated circuit [9] [10].

In the survey paper, some of the basic aspects of the antennas and its types are broadly explained with desired figures. Also, some of the recent researches are surveyed and formulated the problem to get the research gap. The paper sectional organization followed with: In Section 2 the antenna principles are discussed with various categories based types. Section 3 discusses about MsA along with the basic principle of working and different categories in it. In Section 4 various existing feeding techniques for the antenna are discussed. The Section 5 give an overview of related work which identifies all the major research work being done in antennas, MsAs. Later in next Section 6 the research gap is defined following with future scope of research in Section 7. The Section 8 gives the conclusion. 


\section{Background}

An antenna performs the conversion of one form of energy into another. At the receiving end, antenna will convert the electromagnetic-energy into magnetic or electrical energy [3] [4].

- The radiation resistance is the primary parameter of antenna, which relates both the antenna power supply and current flowing within the antenna. The higher radiation resistance will bring more energy to radiate or received by the antenna. Thus, in order to bring the optimality in antenna system, the resistances of the transmitter and or of receiver should be kept equal.

- The antenna pattern is a second of kind parameter of antenna, which indicates the distribution of radiated-power as a direction function in space. Some of these patterns radiate the huge energy in one direction while less energy in other directions.

- The antenna also exhibit the related parameters like gain and directivity in which gain is the ratio of radiated power-to-input power and while the directivity measures the ability of antenna by which antenna concentrate on its radiated power for a given direction.

- The antenna bandwidth is the available frequency outside the center frequency. Example: Consider a transmitter with $10 \mathrm{MHz}$ with bandwidth of $10 \%$ which can send the information over the frequency 9 to $11 \mathrm{MHz}$.

- The next antenna parameter is Signal-to-Noise-Ratio (SNR) indicates the relationship among noise and desired information signal.

\section{Types of Antenna}

The antennas can be categorized [2] [3] [4] as Wire Antenna, Reflector Antenna, Multi-strip Antenna, Aperture Antenna, Lens Antenna and Array Antenna are explained below (Figure 1).

1) Wire Antennas: These kinds of antennas are simple, cheaper and versatile for various applications. The Wire Antenna can be classified as linear, loop and helical. When the wire forms a straight line then it is known as linear Wire Antenna, while wires forming loop are known as loop Wire Antenna. When the wire forms a helical shape is called as helical Wire Antenna (Figure 2).

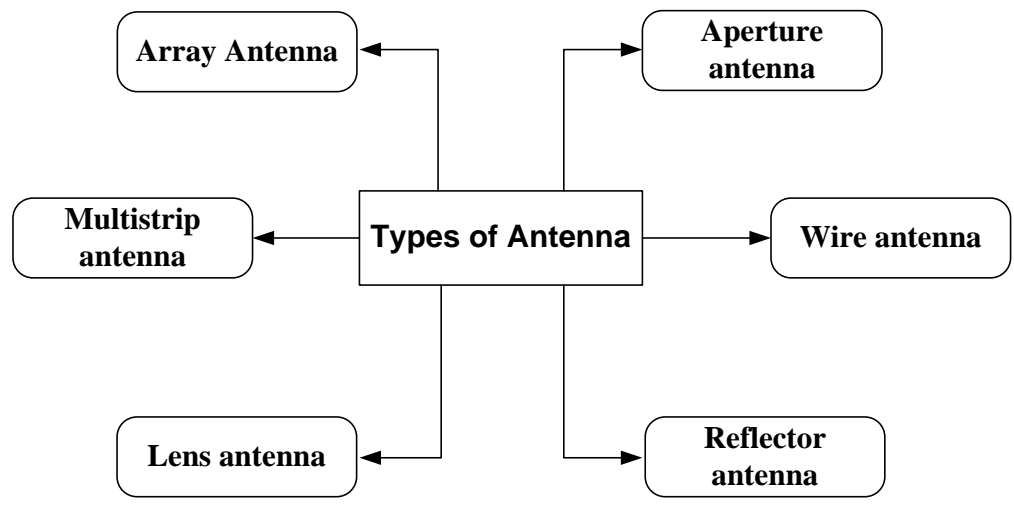

Figure 1. Antenna types. 
2) Aperture Antenna: This kind of antenna is of circular or rectangular horn shape. These antennas can be designed from the "waveguides". Generally, a waveguide is of hollow-metallic-tube shape by which the wave travels. Based on the shape the waveguide can be circular or rectangular. If one tube end is trapped then it acts as antenna. Also, due to the horn shape of the antenna these antennas are known as horn antennas (Figure 3 ).

The Aperture Antenna is formed from the circular/rectangular waveguides. These antennas can transfer a high magnetrons power more than GHZ.

3) Array Antenna: These kinds of antennas are generally formed by various elements because sometimes a single element based antennas cannot offer desired properties. Thus, to achieve this multiple elements can be used in the antenna structure (Figure 4).

4) Lens Antennas: The optics says that the lenses help to collimate the incoming divergent light energy to protect spreading of light in undesired direction. The use of proper shaped lenses can help to transfer various divergent lights in a single plane. The Lens Antennas can be used at higher frequency applications and these antennas need a proper feed mechanism (Figure 5).

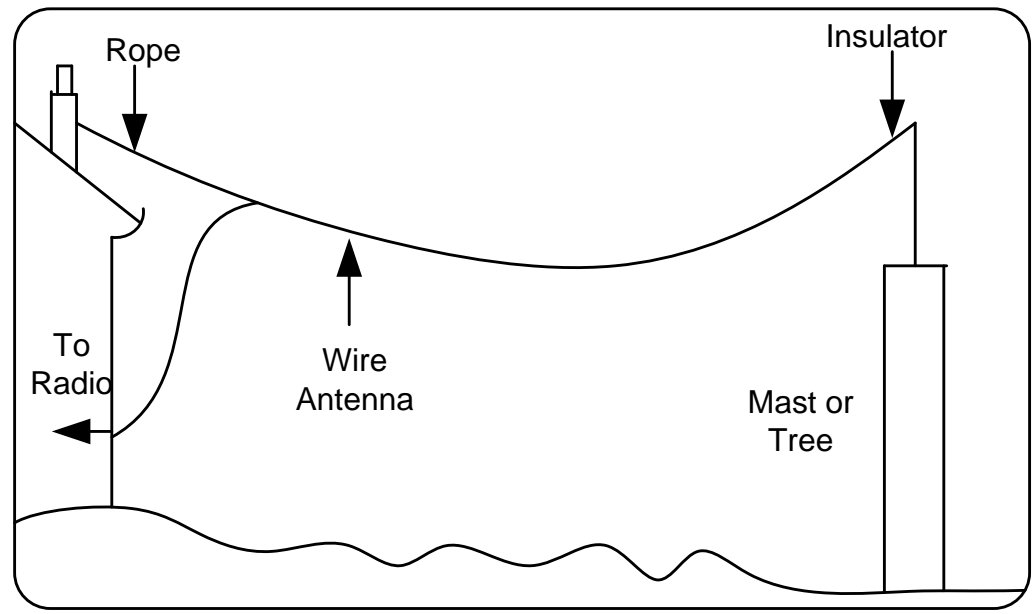

Figure 2. Wire antenna.

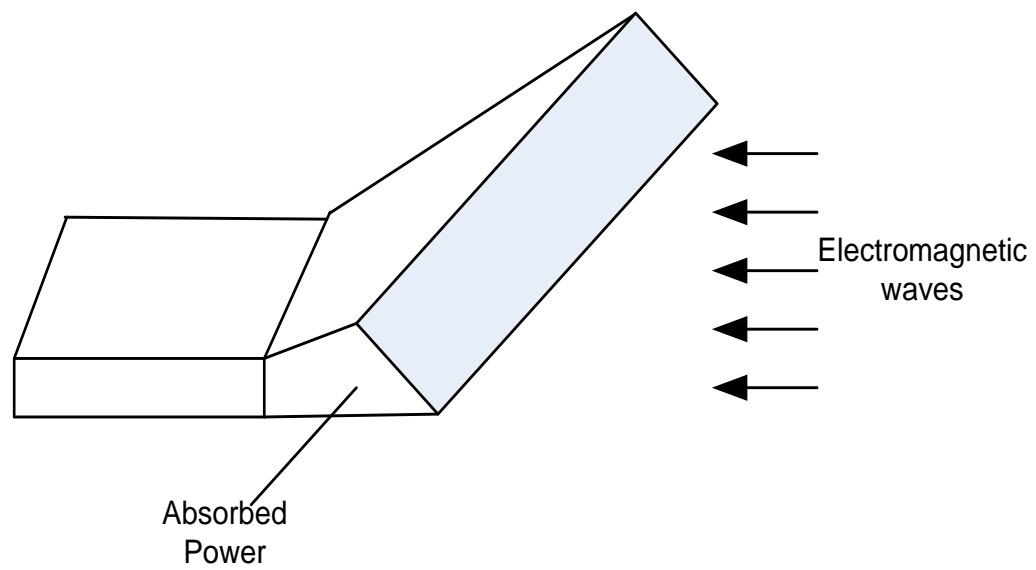

Figure 3. Aperture antenna. 
5) Reflector Antenna: These kind of antennas composed of radiating elements with the reflecting surface. In this the dipole act as radiating element whiles the flat conductor act as reflector to get high directivity. The best form of reflector is parabolic reflector than flat reflector. These reflectors convert spherical waves into the plane waves (Figure 6).

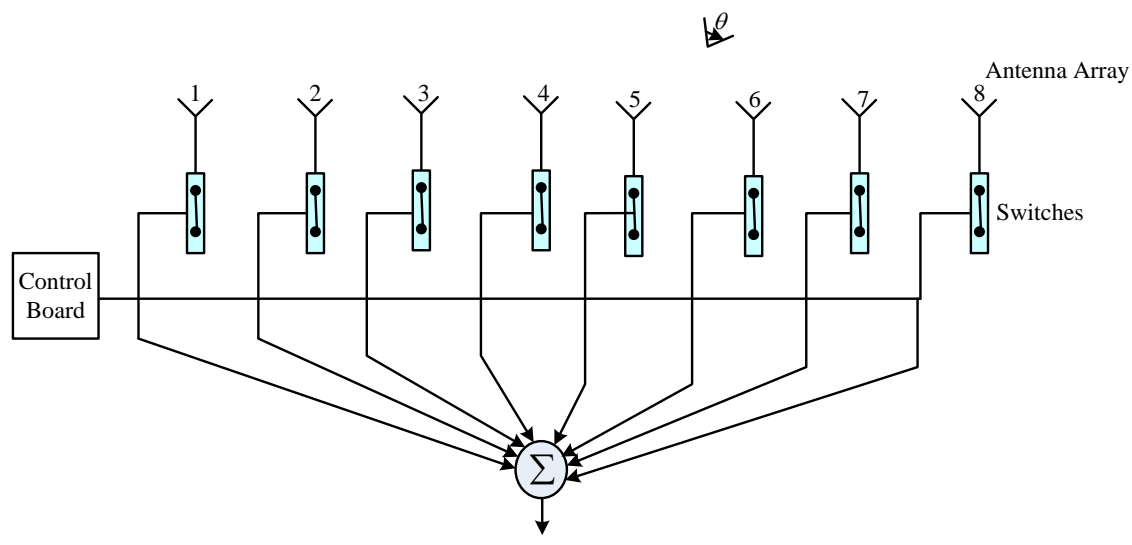

Figure 4. Array antenna.

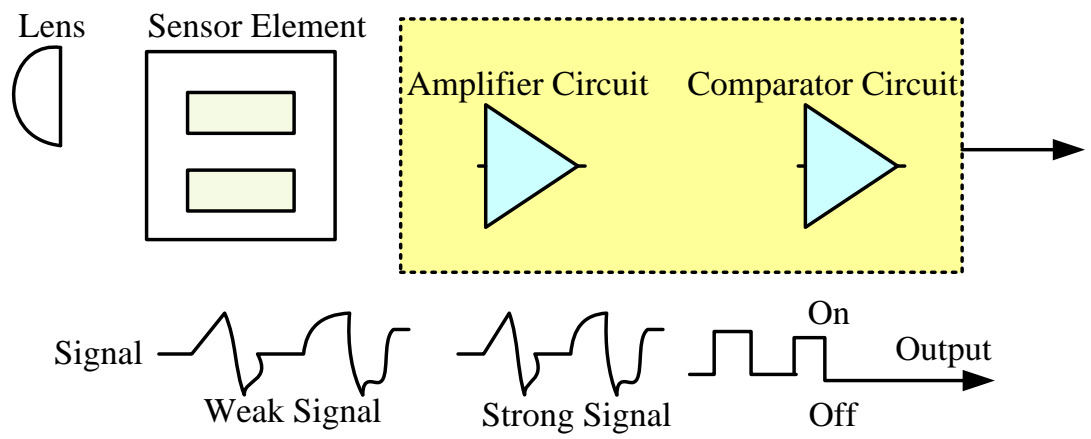

Figure 5. Lens antenna.

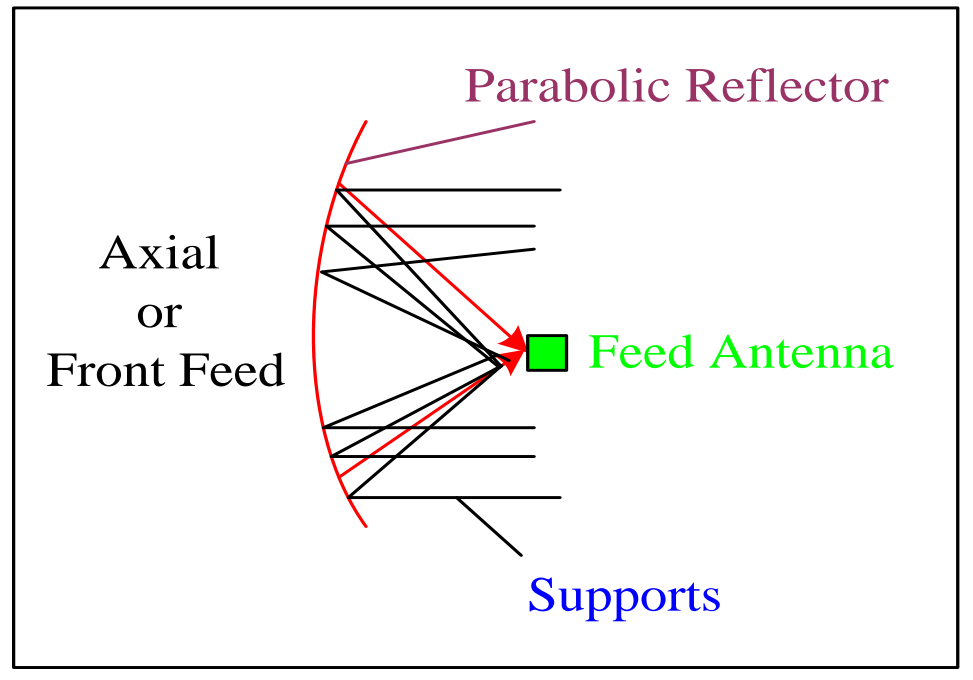

Figure 6. Array antenna. 
6) MsA: This type of antennas have conducting material patches etched on one end of the dielectric substrate, other end contains the " $\mathrm{m}$ " metal ground plane. The MsA act as patch antenna and it can be classified as rectangular, circular, square etc.

\section{MsA}

The Figure 7 shows configuration of the MsA. This contains a radiating patch at dielectric substrate one end and also ground plane at other end [11].

MsA are characterized by the physical parameters other microwave antennas. Based on the geometrical shapes and its dimensions MsA are divided as (Figure 8):

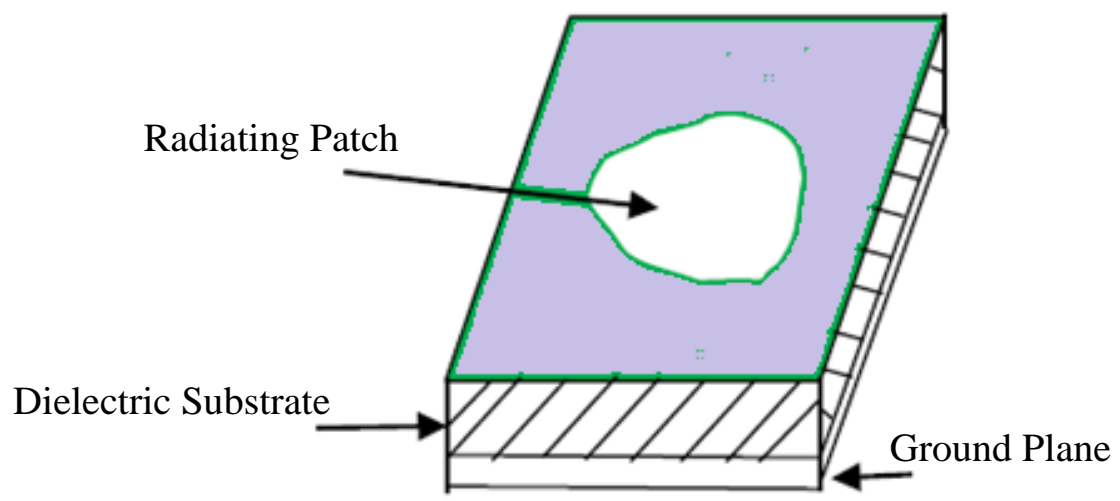

Figure 7. MsA configuration.

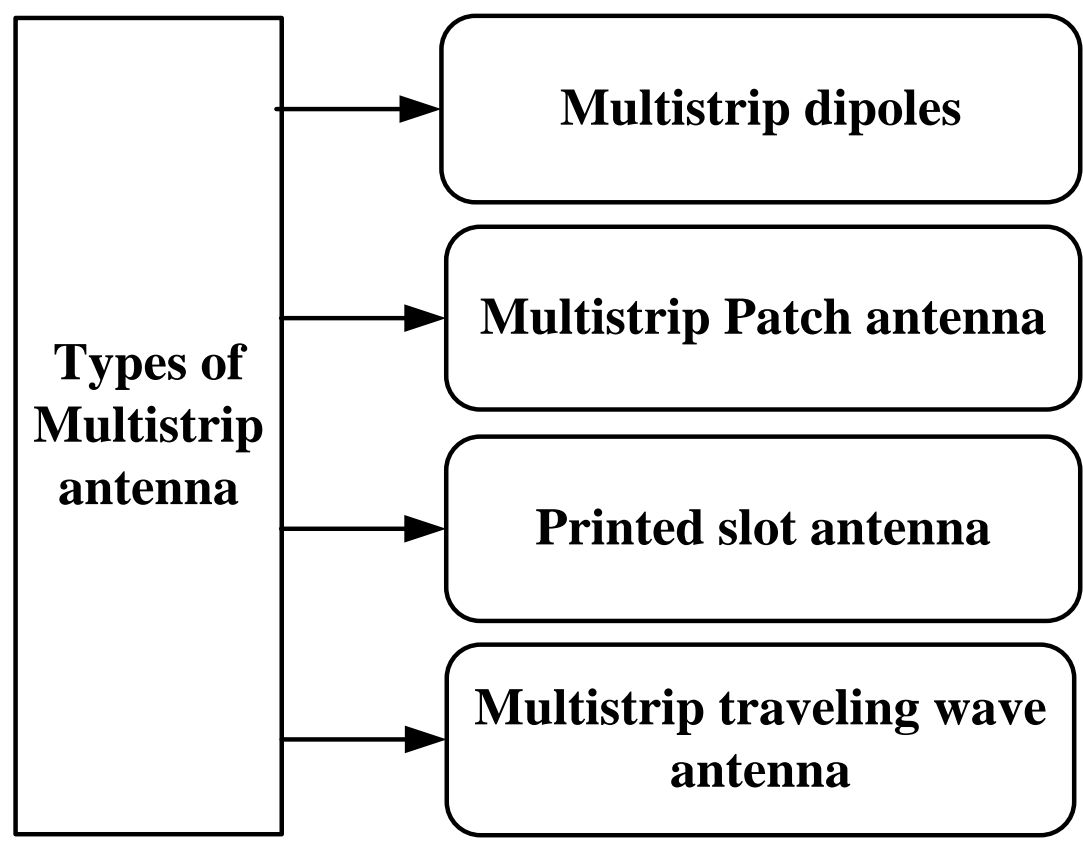

Figure 8. Types of MsA. 
The MsA consists of a conducting patch over a planar or non planar geometry having ground plane at one end while dielectric substrate at other end. The printed resonant antenna for the wireless application needs a coverage semihemispherical shape. Till now very rare number of MsPA were studied [11]. Among the various MsP the rectangular and circular patches are widely utilized MsA. These patches are can be used at simple and at requesting applications. Rectangular geometries are distinct in nature and their analysis is quite simple. Next, the circular patch based antenna consist a upside patterns for radiation symmetry. A rectangular MsPA is given in Figure 9. This antenna contains a radiating patch at one end of a dielectric substrate that consist a ground plane at another end. In this, the patch is made of conducting material i.e., copper or gold. Through radiating patch and the feed lines are usually photo etched on the dielectric substrate. These antennas radiate primarily because of the fringing fields among ground plane and patch edge.

\section{Feeding Technique}

Generally, a feed-line is utilized to activate the radiation by direct or indirect contact. The feeding techniques include coaxial probe feed (CPF), Microstrip line (MsL), aperture coupling (ACo) and proximity coupling (PCo) [12].

\subsection{Coaxial Probe Feeding (CPF)}

The internal coaxial conductor of this feeding mechanism is appended to its antenna patch radiation while the external conductor is given at ground plane. The significant point of this mechanism is that its fabrication is simple; matching is simple, low spurious radiation. The demerit of the feeding mechanism is that it is restricted with limited data transfer capacity; the design process is quite tough for thick substrate (Figure 10).

\subsection{Microstrip Line (MsL) Feed}

This mechanism offers the conducting strip fabrication conducting strip with the associating patch for patch extension. The mechanisms designing are simple

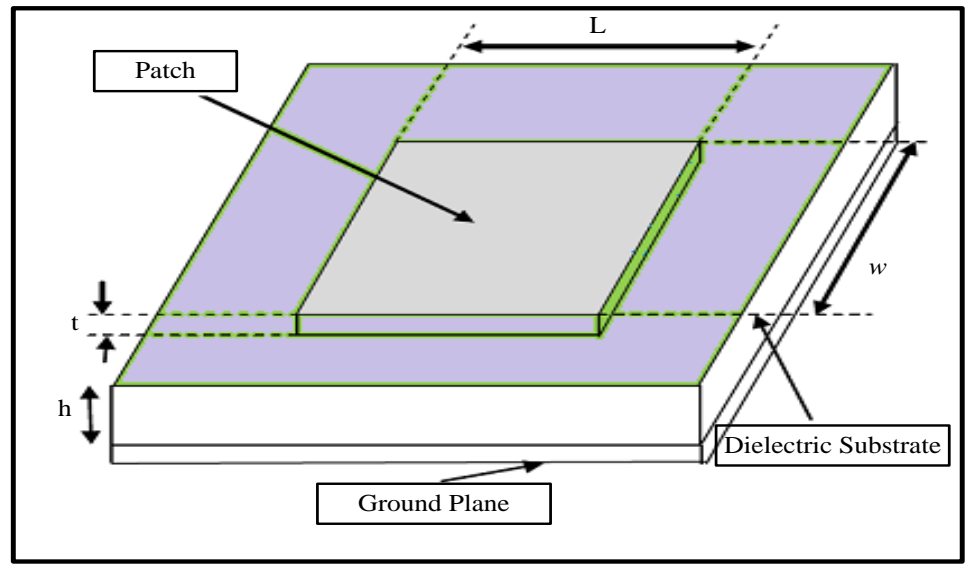

Figure 9. Structure of rectangular MsPA. 
and easier to coordinate. This mechanism increases the SW, substrate thickness, and spurious feed radiation expands which restrain the transfer speed (Figure 11).

\subsection{Aperture Coupled (ACo) Feed Method}

This mechanism includes two diverse substrate isolated by a ground plane. At lower substrate bottom an Ms Line is present and its energy is combined with patch. This permits independent feed mechanism optimization and the radiating element. The ground plane (middle) isolates the feed from radiation element and limits spurious radiation interferences. This method permits independent optimization of feed mechanism element (Figure 12).

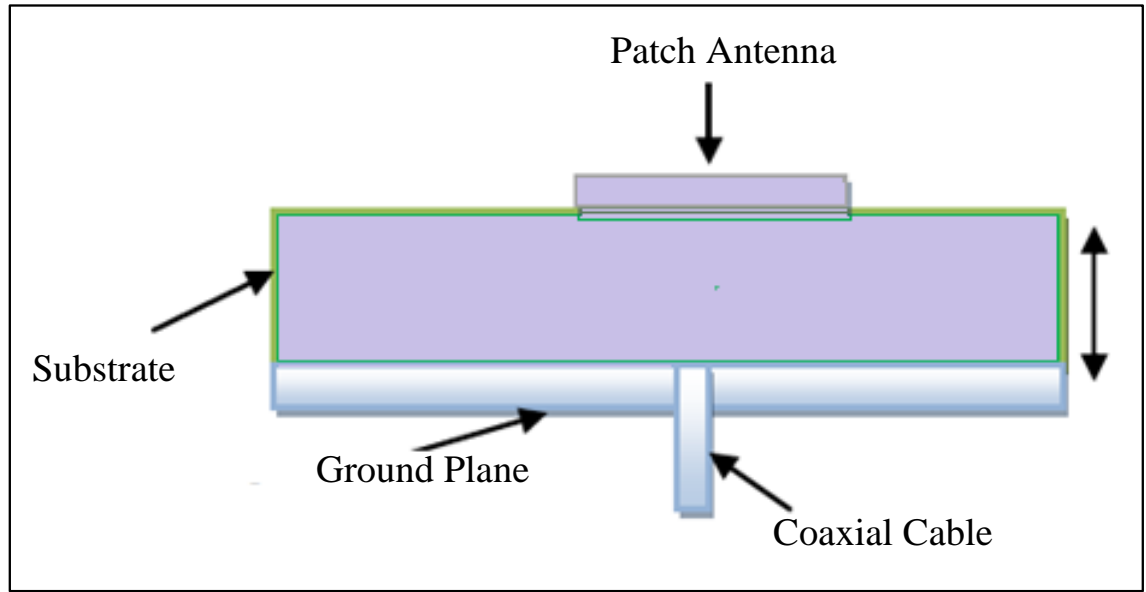

Figure 10. CPF patch antenna.

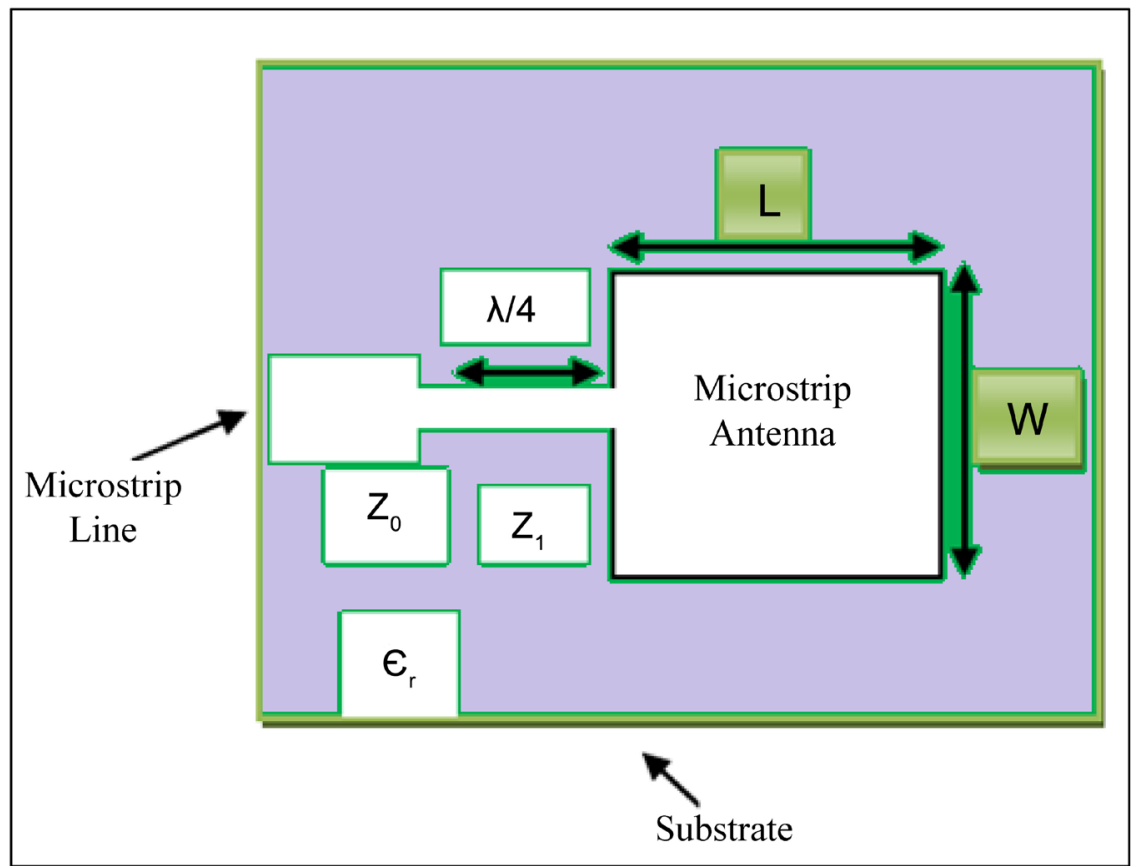

Figure 11. MSL feed patch antenna. 


\subsection{Proximity Coupling}

This method exhibits low spurious radiation with larger bandwidth but difficult fabrication. The feeding length stub and width-to-length patch ratio is considered for controlling the match. The coupling mechanism of Pc is capacitive in nature (Figure 13).

This feeding technique poses drawbacks as it is fabrication is tough due to presence of two dielectric layers requires desired alignment. Also, the overall increment in the antenna thickness is a major concern. Also, the designing of wide range of antenna contains MsA parts like Feed line, patch, Ground plane and Dielectric substrate. In below Table 1, various feeding techniques are compared based on their polarization, reliability, fabrication and bandwidth.

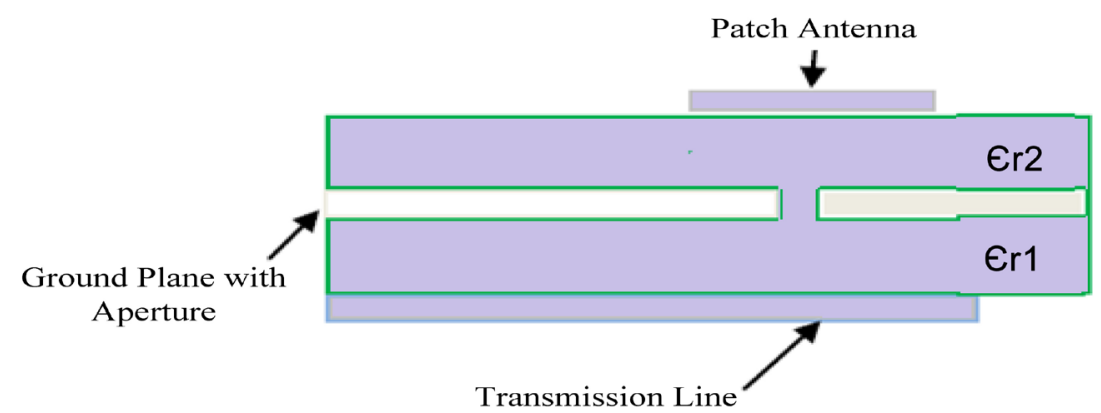

Figure 12. Aperture coupled feed patch antenna.
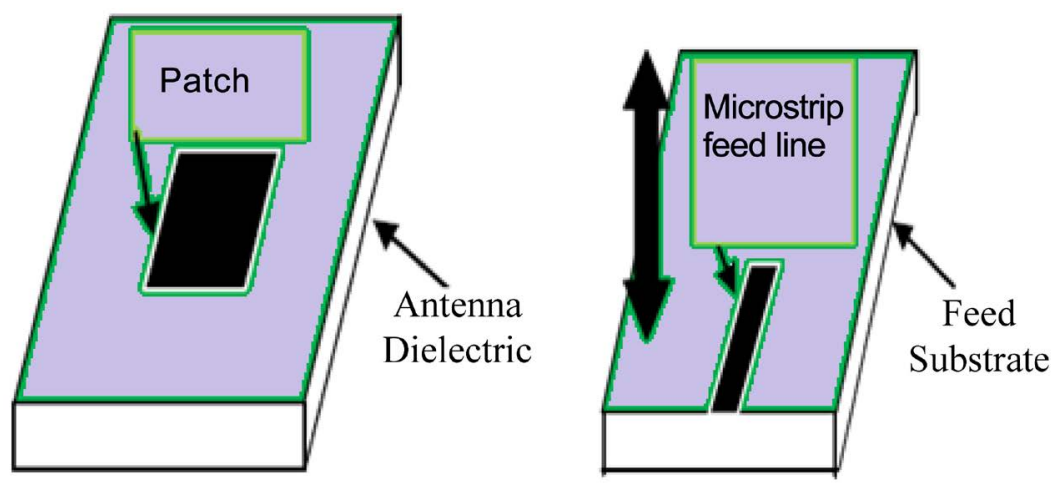

Figure 13. Proximity coupled microstip patch antenna.

Table 1. Feeding techniques comparison.

\begin{tabular}{|c|c|c|c|c|}
\hline $\begin{array}{l}\text { Characteristic } \\
\text { /Technique }\end{array}$ & Polarization & Reliability & Fabrication & Bandwidth \\
\hline Microstrip feed & Poor & Better & Simple & $2 \%-5 \%$ \\
\hline Coaxial feed & Poor & Poor & $\begin{array}{l}\text { Drilling } \\
\text { required }\end{array}$ & $2 \%-5 \%$ \\
\hline Proximity feed & Poor & Good & $\begin{array}{l}\text { Alignment } \\
\text { needed }\end{array}$ & $13 \%$ \\
\hline Aperture feed & Excellent & Good & $\begin{array}{l}\text { Alignment } \\
\text { needed }\end{array}$ & $21 \%$ \\
\hline
\end{tabular}




\section{Existing Research Analysis}

In this unit, the existing researches have been addressed for antenna, more specific to Microstip Patch Antenna. These recent research works are selected from the IEEE Xplore.

In Zhang et al. [13] have presented the Dual-Band Circularly Polarized Patch Antenna having one layer and with single feed. The Dual-Band Circularly Polarized Patch is contains a square-patch and four folded stubs pairs from comers. The senses of Circularly Polarized Radiation at lower \& upper bands can be controlled. Author has discussed the impact of stubs loaded over radiating patch and its design aspects. For validation, a prototype is designed at $4.49 \mathrm{GHz}$ operating condition and fabricated. Form the outcome right and left hand CPR are obtained at lower and upper band and gain of $7.0 \& 5.9 \mathrm{dBic}$ respectively. The work of Katyar and Basu [14] gives an analysis technique of multi-layered stacked Microstip Patch Antenna with transmission-line equivalent circuits. These circuits where examined by Broadband-Stacked Antenna analysis. In this author has developed a circuit model by dividing antenna as pair of metal patches which are developed as transmission-line. In this, a proper procedure is followed for implementation of the proposed method to a multi-layered stacked Microstip Patch Antenna. In the circuit response for three-layered BroadbandStacked Antenna is found with better simulation and measured results. The proposed circuit enables the quicker circuit simulation and better optimization in antenna parameters. Authors Hannachi and Tatu [15] described a comparative study of various antennas with alike shapes suitable for the wireless applications of $60 \mathrm{~Hz}$. The comparison is followed with the outcomes of the radiation characteristics, input return losses followed by determination of the parameters like bandwidth, gain, cross polarization level, voltage ratio (wave) and efficiency.

Wang et al. [16] gives a bandwidth enhancement research in equilateral-triangular $\mathrm{MsPA}$ at differential excitation. The method is validated by giving a prototype antenna and fabricated. As theoretically expected, the impedance bandwidth of the final designed patch antenna has been increased to $50.46 \%$ and the gain is around $6.5 \mathrm{dBi}$. Both simulated and measured results exhibit wide bandwidth and good performance of radiation. In Hamberger et al. [17] planar, dual polarized-patch-antenna (dpPA) is presented with ability of vertical beamforming. This array was designed as three horizontal rows with each having 10 elements. The benchmarking with the existing work was performed based on the measurements and simulation results.

In Brocker et al. [18] a linearly polarized dual-polarized patch antenna with independent band control and low cross-polarization is designed. In this, the miniaturization was attained by shorting the combination/folding and by slot loading. Thus, at lower band operation are fixed and upper band operation are shifted to $10 \%$. The impact of small-ground plane utilization is discussed for small antenna footprint.

The author Jin et al. [19] presented a 4-differential-fed patch antenna array (dfPA) by implanting low temperature co-fired ceramic process. In this, the wi- 
deband patch are used with L-shaped feeding mechanism as antenna element and the differential feeding network with low insertion loss was implanted for antenna array integration. The measured outcome of $10-\mathrm{dB}$ antenna array bandwidth acquires $11.7 \%$ impedance. The peak gain is measured of $18.62 \mathrm{dBi}$ at bandwidth of $61.5 \mathrm{GHz}$ and polarization of $-25 \mathrm{~dB}$.

In Zhang et al. [20] gave a low-profile dual-band filtering antenna. The antenna is further designed for LTE customer premise equipment, where low profile and high integration of multiple components are required. The work of Trong et al. [21] explains the frequency and pattern-reconfigurable antenna based on a center shorted Microstip Patch Antenna. The novel design utilizes two resonance modes of Microstip Antenna with shorting via at the patch center. Based on the proposed concept, a demonstration antenna has been designed so that two types of aforementioned patterns can be reconfigured across a continuous fractional frequency range of more than 20\%. Experimental results are provided which validates the proposed concept and design procedure. The combined study of Li and Liu [22] described the vertically integrated differential filtering antenna. This antenna consists of a differential-fed Microstrip patch, a U-shaped differential resonator, and two pairs of quarter-wavelength J-inverters. All the elements are vertically integrated without increasing the dimensions. It achieves an impedance bandwidth of $5 \%$ with the return loss better than $15 \mathrm{~dB}$, and a gain of $6.85 \mathrm{dBi}$.

A method of generating the millimeter-wave Hermite-Gaussian (HG11) beams using patch antennas is introduced in Yao et al. [23]. This HG11 beam got by using 4 inset-fed MsP elements arranged together with Microstrip corporate feeding network. The antenna size is $8 \times 8 \times 0.125 \mathrm{~mm}^{3}$. In this, a full-wave electromagnetic simulator is used for array design. In Attaran et al. [24] analysis design is presented for Microstrip Rotman (MsR) lens with MsPA array. In the proposed MsR mechanism, the transmission lines length was not affect the progressive phase delay. The MsR lens was designed on the basis of implemented technique consisting of 5 bea and 5 array, 4 dummy ports, and a footprint of less than $11 \mathrm{~mm} \times 10.7 \mathrm{~mm}$ under operating frequency $60 \mathrm{GHz}$ operation frequency. The implemented model and antenna array got a good insertion loss, wide bandwidth, return loss and lowest phase error less than $0.45^{\circ}$ at abnormal scenario. Author Zhang et al. [25] provided a single-layer MsPA that enhances the bandwidth and also harmonic suppression. A prototype antenna is designed which operates at $4.9 \mathrm{GHz}$ and fabricated. The bandwidth of 2.7 achieved.

The combined research of Sun and Rumahi [26] explains a novel proximity coupled cavity backed patch antenna for long range RFID tag. A prototype was fabricated and achieved a gain of $5.7 \mathrm{dBi}$, which gives it a reading range of up to $23 \mathrm{~m}$. In Smyth et al. [27] a novel dual-band MSPA employed with meta-material integrated into its radiating edges to support two distinct operating frequencies is presented. The resulting antenna is compact, uniplanar, completely printable, and via-free. The result achieved gives the radiation performance comparable to other antenna. 
Tang et al. [28] introduced a wideband strip helical antenna with a parasitic circular patch for circular polarization. A strip-helix with 2.5 turns and a pitch angle is placed over a ground plane and coaxial probe-fed connector. The outcome was measured about impedance of $53 \%$, and a peak gain of $9.4 \mathrm{dBi}$ in its volume and the wavelength in free space at the center operation frequency.

Salih and Sharawi [29] presented a highly miniaturized dual-band patch antenna for small form factor devices. The antenna is designed to cover two wireless local area network bands at 2.4 and $5.2 \mathrm{GHz}$. The antenna is miniaturized using a shorting post and a novel defected ground structure. The patch size is 8.8 $\mathrm{m}$ by $10 \mathrm{~mm}$ which means $74 \%$ miniaturization ratio is achieved at $2.4 \mathrm{GHz}$. The dual-band property is achieved by etching a U-slot in the ground as a part of the proposed defected ground structure. The antenna is fabricated on Rogers RO4350 board and its radiation characteristics are measured. The measured results have good agreement with simulated ones. In Liu et al. [30] introduced a method of designing a Dual-Band sector ring MsA and its application. The dual-band sector ring MsA at operating modes TM11 and TM02 were analyzed and then designed in this communication. A novel coupling sector ring patch was then proposed to improve the performance of the antenna. The study results are in good agreement with the analyses and the simulations. The impedance antenna bandwidths are 40 and $900 \mathrm{MHz}$ with radiation patterns at $2.4 \mathrm{GHz}$ and $5.5 \mathrm{GHz}$ band.

Shen et al. [31] have introduced a MsA array by utilizing a sequential-rotated feed networks in order to attain the dual circular polarization at same band. By interlacing the MsPA of adjacent $2 \times 2$ sub-arrays, the element spacing was minimized to avoid the challenging grating lobes issue. Also, the radiating elements are reduced from $4 \mathrm{~N}$ to $2 \mathrm{~N}+2$, where $\mathrm{N}$ is the number of $2 \times 2$ sub-arrays. The validation is carried by fabricating the prototype. In Liu et al. [32] introduced a novel design concept for bandwidth enhancement in the dfPA with dual-resonant radiation. The Stepped-Impedance-Resonator (SIR) used, which contains two portions like radiating patch and open stubs pair. By using the Transmission Line (Tx) model, the first and resonant (TM10 \& TM30) modes of this SIRtyped patch antenna was analyzed. The designed antenna attains a stable gain of 7.4-to-8.5 $\mathrm{dB}$ at operating band and at low-cross polarization.

Tao and Guang [33] proposed an MsPA annular array in order to excite the high order (TE01) mode in circular waveguide. The array consists of four MsPA which are laid and fed rotationally. In this model, the transmission and receiver antenna was utilized as proposed annular array and dipole antenna respectively. From the analysis found the lesser annular array transmission loss than the dipole.

Liang et al. [34] introduced a Ms end-fire array antenna of vertical polarization. The array element composed of two symmetrical-rectangular patches at both the end of the substrate with two shorted edges and other opened edges. A 2-element $(2-\mathrm{eFa})$ and a 4 -element end-fire array $(4-\mathrm{eFa})$ were proposed to attain end-fire vertical polarization at low profile of $3 \mathrm{~mm}$. The 2-eFa exhibit 
bandwidth of 2.42 -to-2.48 GHz and a peak end-fire gain of $5.3 \mathrm{dBi}$. While 4 -eFa attains the peak end-fire gains of $7.7 \mathrm{dBi}$ at bandwidth 2.40 -to-2.48 GHz.

Dong et al. [35] introduced the concept of dual-band reconfigurable terahertz patch antenna using a graphene-stack-defined backing cavity is presented. The proposed antenna employs patch resonance based on backing cavity defined by interleaved graphene $/ \mathrm{Al}_{2} \mathrm{O}_{3}$ stacks, which can be dynamically dual resonance frequency-tuned on large range about $1 \mathrm{THz}$ via electrostatic gating on the graphene stack. The performance is analyzed in terms of its directivity, side lobe suppression, return loss and bandwidth for different chemical potential. By applying different voltages on graphene stack, antenna direction main beam can be steered with appreciable variation range. In Hamberger et al. [17] provides a planar dual-polarized patch antenna array with vertical beam forming capability. The array is designed in terms of three horizontal rows consisting of ten elements each. They are fed in series transmission line architecture and the design frequency was chosen to $24.125 \mathrm{GHz}$, at $24 \mathrm{GHz}$ ISM-band. The novelties and the potential of this dual-polarized antenna array are discussed in detail and its characteristics are brought forward by simulation and measurement results.

\section{Research Gap}

After reviewing the existing research techniques towards upgrading the overall performance of Microstrip Patch Antenna, it has been seen that there has been various research attempts with significant contribution. However, there are certain pitfalls in the existing studies too which give rise of various forms of unsolved question. Hence, the brief of the existing research gaps towards Microstrip patch antenna are as follow:

- Less focus on accuracy: Although, existing techniques are more focused on upgrading the performance of Microstrip patch antenna, it misses addressing the problems associated with accuracy along with speedy response. Usage of explicitly full-wave with discrete value along with an effective electromagnetic simulation-based approach is not enough to ensure accuracy. There are vast number of adjustable attributes in MsPA which requires more attention during the design process e.g. excitation taper information, spacing between array, element's dimension, location and shape of feed, etc.

- Lack of integrated mechanism in design process: Existing studies are too much inclined on introduced any one forms of MsPA and less focus on hybridizing it. Studies towards U-Slot antenna are abundant in literature but it has never being used for feature mode evaluation. Studies using empirical approaches are less while more is on simulation/hardware based. Therefore, it misses out the probability of using resonant frequency to upgrade the performance of MsPA.

- Few attempts towards optimization: Although, optimization problems has reached its peak success in computer networks as well as other wireless communication system, but it has received less number of attention in the area of MsPA. 
From IEEE Xplore [36], following details are found regarding the existing researches by proving keywords "Microstrip patch antenna + Accuracy + Optimization". The details found with the above keyword include 216 Conference Publications and 143 Journals \& Magazines. Similarly 714 Conference Publications, 193 Journals \& Magazines, 4 Early Access Articles and 2 Standards are after providing keyword "Microstrip patch antenna + integrated mechanism in design process".

\section{Conclusions}

In this paper, various aspects related antenna design; antenna aspects for wireless communication are discussed. The wireless communication in today's genre plays vital role in almost all the areas. But maintaining/attaining a better communication is bigger issues. There were many techniques have been proposed to attain better communication. The antenna system is a known technique which provides a better information transmission and receiving. In this paper various aspects of the MsA are discussed along with the existing researches which are more specific to microstrip patch antenna. After analyzing these existing reseaches, a research gap is formulated by which it is found that less focus on accuracy, lack of integrated mechanism in design process and few attempts towards optimization are exist. For proof some of the existing details from IEEE Xplore are presented.

The future line of research needs a proper and effective analysis on the existing issues, needs to develop some integrated design to enhance the performance of the MsPA. Also, the future study needs to concentrate on the accuracy parameters of MsPA such as array pattern, element's dimension, location and shape of feed, etc. The futuristic models should have special optimization ability.

\section{References}

[1] David, T. and Viswanath, P. (2005) Fundamentals of Wireless Communication. Cambridge University Press, Cambridge.

[2] Alejandro, A.-Z. (2008) Antennas and Propagation for Wireless Communication Systems. John Wiley \& Sons, Hoboken.

[3] Balanis, C.A. (2016) Antenna Theory: Analysis and Design. John Wiley \& Sons, Hoboken.

[4] Winters, J.H., Jack, S. and Richard, D.G. (1994) The Impact of Antenna Diversity on the Capacity of Wireless Communication Systems. IEEE Transactions on Communications, 42, 1740-1751. https://doi.org/10.1109/TCOMM.1994.582882

[5] Winters, J.H. (1998) Smart Antennas for Wireless Systems. IEEE Personal Communications, 5, 23-27. https://doi.org/10.1109/98.656155

[6] Salvatore, B., et al. (2002) Smart-Antenna Systems for Mobile Communication Networks. Part 1. Overview and Antenna Design. IEEE Antennas and Propagation Magazine, 44, 145-154. https://doi.org/10.1109/MAP.2002.1039395

[7] Tsoulos, G.V. (1999) Smart Antennas for Mobile Communication Systems: Benefits and Challenges. Electronics \& Communication Engineering Journal, 11, 84-94. https://doi.org/10.1049/ecej:19990204 
[8] Salvatore, B., et al. (2002) Smart-Antenna Systems for Mobile Communication Networks. Part 2. Beamforming and Network Throughput. IEEE Antennas and Propagation Magazine, 44, 106-114. https://doi.org/10.1109/MAP.2002.1039395

[9] Ramesh, G. (2001) MsA Design Handbook. Artech House Publishers, Norwood.

[10] Ujjal, C., et al. (2011) A Comact Microstrip Patch Antenna for Wireless Communication. Progress in Electromagnetics Research C, 18, 211-220. https://doi.org/10.2528/PIERC10101205

[11] Indrasen, S. and Tripathi, V.S. (2011) Micro Strip Patch Antenna and Its Applications: A Survey. International Journal of Computer Technology and Applications, 2 , 1595-1599.

[12] Varshney, H.K., et al. (2014) A Survey on Different Feeding Techniques of Rectangular Microstrip Patch Antenna. International Journal of Current Engineering and Technology, 4, 1418-1423.

[13] Zhang, J.-D., et al. (2016) CP Patch Antenna with Controllable Polarisation over Dual-Frequency Bands. IET Microwaves, Antennas \& Propagation, 11, 224-231. https://doi.org/10.1049/iet-map.2016.0216

[14] Ankita, K. and Basu, A. (2016) Analysis and Optimisation of Broadband Stacked MsAs Using Transmission Line Model. IET Microwaves, Antennas \& Propagation, 11, 81-91.

[15] Chaouki, H. and Tatu, S.O. (2016) Performance Comparison of $60 \mathrm{GHz}$ Printed Patch Antennas with Different Geometrical Shapes Using Miniature Hybrid Microwave Integrated Circuits Technology. IET Microwaves, Antennas \& Propagation, 11, 106-112

[16] Wang, J.P., Liu, Q.W. and Lei, Z. (2017) Bandwidth Enhancement of a Differential-Fed Equilateral Triangular Patch Antenna via Loading of Shorting Posts. IEEE Transactions on Antennas and Propagation, 65, 36-43. https://doi.org/10.1109/TAP.2016.2630660

[17] Hamberger, G.F., et al. (2017) A Planar Dual-Polarized Microstrip 1-D-Beamforming Antenna Array for the 24-GHz Band. IEEE Transactions on Antennas and Propagation, 65, 142-149. https://doi.org/10.1109/TAP.2016.2618847

[18] Brocker, D.E., et al. (2016) Miniaturized Dual-band Folded Patch Antenna with Independent Band Control Utilizing an Interdigitated Slot Loading. IEEE Transactions on Antennas and Propagation, 65, 380-384. https://doi.org/10.1109/TAP.2016.2627025

[19] Jin, H., et al. (2015) High-Gain Low-Cross-Polarization 60-GHz LTCC Patch Antenna Array with Differential-Fed and Soft-Surface Structures. Microwave Conference (APMC), 2015 Asia-Pacific, 1, 1-3.

[20] Zhang, X.Y., et al. (2017) Low-Profile Dual-Band Filtering Patch Antenna and Its Application to LTE MIMO System. IEEE Transactions on Antennas and Propagation, 65, 103-113. https://doi.org/10.1109/TAP.2016.2631218

[21] Nghia, N.-T., Hall, L. and Fumeaux, C. (2016) A Frequency and Pattern Reconfigurable Center-Shorted MsA. IEEE Antennas and Wireless Propagation Letters, 15, 1955-1958. https://doi.org/10.1109/LAWP.2016.2544943

[22] Lin, L. and Liu, G. (2016) A Differential MsA with Filtering Response. IEEE Antennas and Wireless Propagation Letters, 15, 1983-1986.

https://doi.org/10.1109/LAWP.2016.2547884

[23] Yao, H.H., et al. (2016) Patch Antenna Array for the Generation of Millimeter-Wave Hermite-Gaussian Beams. IEEE Antennas and Wireless Propagation Let- 
ters, 15, 1947-1950. https://doi.org/10.1109/LAWP.2016.2544808

[24] Ali, A., Rashidzadeh, R. and Kouki, A. (2016) 60 GHz Low Phase Error Rotman Lens Combined with Wideband MsA Array Using LTCC Technology. IEEE Transactions on Antennas and Propagation, 64, 5172-5180. https://doi.org/10.1109/TAP.2016.2618479

[25] Zhang, J.-D., et al. (2016) A Compact Microstrip-Fed Patch Antenna with Enhanced Bandwidth and Harmonic Suppression. IEEE Transactions on Antennas and Propagation, 64, 5030-5037. https://doi.org/10.1109/TAP.2016.2618539

[26] Sun, H., Bo, T. and Ramahi, O.M. (2016) Proximity Coupled Cavity Backed Patch Antenna for Long Range UHF RFID Tag. IEEE Transactions on Antennas and Propagation, 64, 5446-5449. https://doi.org/10.1109/TAP.2016.2606881

[27] Smyth, B.P., Barth, S. and Iyer, A.K. (2016) Dual-Band Microstrip Patch Antenna Using Integrated Uniplanar Metamaterial-Based EBGs. IEEE Transactions on Antennas and Propagation, 64, 5046-5053. https://doi.org/10.1109/TAP.2016.2618854

[28] Tang, X.H., He, Y.J. and Feng, B.T. (2016) Design of a Wideband Circularly Polarized Strip-Helical Antenna with a Parasitic Patch. IEEE Access, 4, 7728-7735. https://doi.org/10.1109/ACCESS.2016.2628044

[29] Salih, A.A. and Sharawi, M.S. (2016) A Dual-Band Highly Miniaturized Patch Antenna. IEEE Antennas and Wireless Propagation Letters, 15, 1783-1786. https://doi.org/10.1109/LAWP.2016.2536678

[30] Liu, X.Y., et al. (2016) A Method of Designing a Dual-Band Sector Ring MsA and Its Application. IEEE Transactions on Antennas and Propagation, 64, 4896-4901. https://doi.org/10.1109/TAP.2016.2596903

[31] Shen, Y.Z., et al. (2016) A Compact Dual Circularly Polarized Microstrip Patch Array with Interlaced Sequentially Rotated Feed. IEEE Transactions on Antennas and Propagation, 64, 4933-4936. https://doi.org/10.1109/TAP.2016.2600747

[32] Liu, N.-W., et al. (2016) A Novel Differential-Fed Patch Antenna on Stepped-Impedance Resonator with Enhanced Bandwidth under Dual-Resonance. IEEE Transactions on Antennas and Propagation, 64, 4618-4625. https://doi.org/10.1109/TAP.2016.2606583

[33] Chen, H.-T. and Zhang, Z.-G. (2016) Compact Microstrip Patch Array Used to Radiate TE01 Mode Wave in Circular Waveguide. Electronics Letters, 52, 1776-1778. https://doi.org/10.1049/el.2016.2824

[34] Liang, Z.X., et al. (2016) Microstrip Magnetic Monopole Endfire Array Antenna with Vertical Polarization. IEEE Transactions on Antennas and Propagation, 64, 4208-4217. https://doi.org/10.1109/TAP.2016.2597643

[35] Dong, Y.F., et al. (2016) Dual-Band Reconfigurable Terahertz Patch Antenna with Graphene-Stack-Based Backing Cavity. IEEE Antennas and Wireless Propagation Letters, 15, 1541-1544. https://doi.org/10.1109/LAWP.2016.2533018

[36] IEEE Xplore (2017) IEEE Xplore Digital Library. http://ieeexplore.ieee.org/Xplore/home.jsp 
Submit or recommend next manuscript to SCIRP and we will provide best service for you:

Accepting pre-submission inquiries through Email, Facebook, LinkedIn, Twitter, etc. A wide selection of journals (inclusive of 9 subjects, more than 200 journals)

Providing 24-hour high-quality service

User-friendly online submission system

Fair and swift peer-review system

Efficient typesetting and proofreading procedure

Display of the result of downloads and visits, as well as the number of cited articles Maximum dissemination of your research work

Submit your manuscript at: http://papersubmission.scirp.org/

Or contact ojapr@scirp.org 